Article

\title{
An Integrated Industry-Based Methodology to Unlock Full-Scale Implementation of Phosphorus Recovery Technology
}

\author{
Augusto Bianchini * (D) and Jessica Rossi \\ Department of Industrial Engineering, University of Bologna, 40121 Forlì, Italy; jessica.rossi12@unibo.it \\ * Correspondence: augusto.bianchini@unibo.it; Tel.: +39-0543-374438
}

Received: 7 November 2020; Accepted: 16 December 2020; Published: 19 December 2020

\begin{abstract}
The recovery of phosphorus $(\mathrm{P})$ from waste streams in specific industrial processes could really contribute to a more sustainable $\mathrm{P}$ supply chain, which is considered critical due to its high-risk economic relevance and to negative impacts on the environment. Although more than 30 types of $\mathrm{P}$ recovery technologies are already available, their full-scale implementation is not widespread. To make solutions for P recovery in the industrial sector mainstream, it is necessary to change the perception of companies that own flows rich in $\mathrm{P}$, often considered an issue. The lack of decision-making tools and methodologies to identify the optimal solution for specific cases limits the diffusion of $P$ recovery technologies. To unlock this situation, this paper proposes an integrated industry-oriented methodology to facilitate knowledge transfer from the scientific community to the industrial sector, supporting companies in the evaluation of technical, economic, environmental and social benefits/risks of P recovery. The methodology, applied to an Italian case study, uses both innovative and consolidated tools to provide quantitative information at the firm level to investigate a closed P loop: starting from mapping $\mathrm{P}$ flows in the industrial process, the methodology guides companies in the choice of the most suitable option for its business strategy, providing data to evaluate the economic feasibility of the investment and some Key Performance Indicators (KPIs) to assess and monitor their efficiency in managing P. The methodology can be replicated in other contexts by both companies and consultants to explore and disseminate the opportunity to recover and reuse $\mathrm{P}$ from industries. The evaluation of the selected KPIs can be integrated into scientific analyses to compare solutions and to accelerate the shift from pilot to full-scale implementation of promising technologies. Finally, it can be used as an exercise for the training of new professionals in the P management sector.
\end{abstract}

Keywords: phosphorus management; material flow analysis; economic feasibility; waste streams; impact assessment

\section{Introduction}

Numerous researches on phosphorus $(\mathrm{P})$ and its management have been conducted for several decades. The insertion of phosphate rocks in 2014 and of phosphorus in the list of Critical Raw Materials for European Union (EU) in 2017 [1] further boosted research on P. The criticalities of these forms of $\mathrm{P}$ are related to their high economic relevance and high-risk supply chain due to $\mathrm{P}$ scarcity, price volatility and geopolitical factors, determined by the concentration of $\mathrm{P}$ mines in a few extra-EU Countries (China, United States, Morocco and Russia) [2,3]. Moreover, the dissipative nature of P, excessively used without recovery and recycling, determines other negative environmental impacts on soil and water bodies, such as anoxia and uncontrolled eutrophication [4]. A more sustainable model to manage $\mathrm{P}$, based on the circular economy paradigm, consists of the recovery of $\mathrm{P}$ from some 
waste streams, such as wastewater, sewage sludge and sewage sludge ashes, and its reuse in new products, such as fertilizers, which consume the greatest part of mined P worldwide, ensuring crop and animal production systems. A circular model for $P$ is widely recognized as a promising solution for this essential, unreplaceable but limited nutrient to address EU independency from P imports and to achieve resilience in food supply chains [5,6]. A more sustainable use of nutrients (including P) and the stimulation of secondary resource markets are priorities also in the recent European Green Deal (COM(2019) 640 final [7]) and Circular Economy Action Plan (COM(2020) 98 final [8]). The importance of progress in this direction was also recognized by two communities of the European Institute of Innovation and Technology (EIT), an EU body created to strengthen Europe's ability to innovate via funding of innovative projects. In particular, both EIT RawMaterials and EIT Climate KIC considered $\mathrm{P}$ management to be a relevant sector to be inserted in their portfolios of innovations. The InPhos project (no. 17.022, 2018-2020), funded by EIT RawMaterials, identified the main barriers of a more sustainable P management in Baltic Sea Countries, providing several recommendations and practical actions to improve the negative impacts in this EU area. The project Prosumer-Techno-economic and environmental feasibility study of Phosphorus recovery and reuse in fertilizers applied to Italian Prosumers (producers and consumers of P) (no. 200103, 2020), funded by EIT Climate KIC, aimed to identify the techno-economic conditions that make the implementation of a P recovery technology feasible in Italian food companies.

In this context, $\mathrm{P}$ and its management remain relevant topics in scientific literature, which shows an increasing interest in this field, also due to its complexity and multidisciplinarity. More than 30 processes to recover phosphorus from waste streams have been already found and verified, and extensive knowledge has been developed about the analytical processes of P recovery, concerning the dynamics, characteristics, quality and toxicity of derived compounds $[9,10]$. The available technological approaches and components on which available solutions are focused are mainly the following five: struvite (crystals of magnesium ammonium phosphate) precipitation from liquid fraction from different steps of wastewater treatment (1) and sludge after digestion (2), wet chemical $\mathrm{P}$ recovery through an acid attack of ash leaching phosphates (3), thermal solubilization of phosphates in ash determining also a reduction of heavy metals (4) and use of ash for fertilizer manufacturing (5) [11]. Although many different pathways have been analysed and developed in recent years for P recovery and reuse, full-scale implementation of $P$ technologies is not still widespread. Recent studies [11,12] investigated the main barriers and drivers for effective circular management of $\mathrm{P}$, which can be categorized into political/strategical, economic, social, technological, legislative and environmental aspects. Although these aspects cover different disciplines and sectors, it is not difficult to note the interrelations and interdependency among them. However, tackling the question about why full-scale implementation of P recovery is not widespread, surely a discrepancy arises between the literature which affirms that widespread applications of $\mathrm{P}$ recovery technologies could increasingly and significantly contribute to the demand for P, ensuring also safe conditions to obtain the products $[3,13]$, and that the perception of P-rich flow "owners", who consider P management rather than P recovery to be the main objective, is perceived as an issue to be solved to reduce maintenance and operation costs [14]. This lack of awareness about the exploitable potential in waste streams is also directly confirmed in Reference [12], where an interviewee's quote is reported: "If you talked about phosphate recycling 4-5 years ago, nobody had a clue what you were talking about [ ... ], now it is much more of an issue." To go beyond this first limiting incongruity, it is necessary to unlock at least an interest in exploiting P recovery as an opportunity and hence to undertake an assessment about it to finally support decision-making process. According to Reference [14], only an integrated model of the proposed solutions to recover $\mathrm{P}$, including several aspects such as effluent quality, resource efficiency and recovery, environmental impact and costs, can effectively reveal the benefits and limitations. It is fundamental since, without an overview of the benefits and limitations, a company cannot make decisions [15]. 
This contribution deals with providing necessary tools for companies owning P-rich waste streams to investigate the potential associated with $P$ recovery through a change in their perception: thinking of $\mathrm{P}$ recovery as an opportunity and not as an issue. This change is a fundamental step to make the full implementation of $P$ recovery technologies mainstream and hence to take steps forward in the reuse of recovered $P$ in fertilizers, which now still counts as economic and technological barriers [11,12]. The scientific contributions to the implementation of P recovery technologies typically address one specific topic about P management, such as necessary strategical actions, technical aspects, cost assessment and, recently, environmental impact. Even if the results and statements derived from these studies are relevant for academic and scientific communities to upgrade their knowledge in this field and to identify further needed in-depth researches, knowledge transfer in the industrial context is not so easy. Instead, transferring concepts in companies is fundamental, since they enable practical implementation of more sustainable P management and achieve effective impacts. Moreover, studies that aimed to quantify the size and, hence, the impacts of different secondary sources rich in $\mathrm{P}$ highlighted that industries and, above all, food processing have great potential in terms of $\mathrm{P}$ recovery and reuse: for example, in Reference [16], it was demonstrated that the greatest part of $P$ processed by food and non-food production is lost and that the industrial sector represents one of the most dissipative sources of $\mathrm{P}$, after animal manure and urban wastewater. Consequently, the research question addressed by this paper is as follows: How and in which form can scientific knowledge about $P$ support companies in covering the gap between conceptualization and practical implementation of $P$ recovery, achieving "tangible" beneficial effects? Having in mind this question, the main research aspects addressed by the current literature about $\mathrm{P}$ have been analysed in the following points: for each aspect, the main objectives and approaches are considered, and issues in transferring their knowledge and results in the industrial context are highlighted. This review does not have the ambition to be complete and to go in depth about every considered aspect, but it aims to highlight how they are necessary but not sufficient themselves to make the full-scale implementation of P recovery mainstream.

(i) Assessment of $\mathrm{P}$ flows. Several studies about $\mathrm{P}$ aim to analyse and quantify the relevant flows and stocks of $\mathrm{P}$ in the anthropogenic cycle through Material/Substance Flow Analysis (M/SFA) applied to different geographical scales [17], for which only few examples are reported: global [18], continental [16], country [19], regional [20] and city [21]. However, spatial and temporal implications of the tool, related respectively to the selection of geographical or administrative boundaries and the collection and evaluation of data in a specific timeframe (typical on annual basis), determine a static analysis that does not reveal progresses and/or impacts of specific strategies [22,23]. Another typical approach adopted in several studies is based on the characterization of wastewater in industrial processes in terms of pollutants, considering also P concentration [24-30]. However, considering these on the national/regional/local level does not provide useful information at the firm level, characterized by specific features and differences within the same sector.

(ii) Technologies for $P$ recovery. Periodically, research studies collect and compare upgraded information about $P$ recovery technologies, applications and performances. Some examples both in scientific and grey literature are References [31-34]. The typical aim of the cited studies is to highlight already available solutions for different waste streams and operating conditions. Recently, some authors have collected barriers and shortcomings that prevent the diffusion of these solutions at the industrial level. Issues related to optimization of operating conditions, such as chemical dosage, process velocity and stability, formation of undesirable compounds and quality/purity of derived products are the main technical challenges, differently combine in the available solutions [35]. In Reference [36], among the technical limitations, there is the lack of decision-making tools and methodologies to identify the optimal solution for the specific context. In fact, the most suitable solution of $P$ management must be analysed and selected for each single company [13], limiting the direct transfer of results obtained in other applications. 
(iii) Cost assessment of P recovery. According to Reference [37], one of the most limiting aspects for full-scale implementation of $P$ recovery technologies is the lack of consistent and reliable information about costs. The quantity and quality of cost data can be inconsistent due to these data often being extrapolated from lab- or pilot-scale applications or referring to specific conditions. To cover this gap, some research studies have focused on assessment of the economic feasibility of industrial-scale implementations [32,37-39]. As highlighted by quantitative results of the cited studies, the economic feasibility of solutions based on P recovery varies a lot in relation to the initial P concentration, the installed technology, the plant size and the quality of obtained products. A cost assessment is fundamental for comparison of the alternatives and selection of optimal solutions. The availability of reliable and updated cost data is both a fundamental aspect and a challenge [37].

(iv) Environmental assessment of $P$ recovery. The environmental implications of $P$ recovery is less explored than previously described aspects in this topic, and its investigation is recent [40]. Few studies based on Life Cycle Assessment (LCA) have been developed to explore nutrient recovery technologies [41]. The typical approach in the referenced studies [40,42-44] is the comparison of environmental impacts in different scenarios, characterized by the evaluation of different technologies and waste streams in specific operating conditions. Consequently, quantitative results about environmental impact are strictly related to the specific application, making it difficult to obtain evidence about the implications of $P$ recovery. It derives that further analyses about $P$ recovery systems are necessary to know their effective environmental impacts [40]. Nevertheless, companies that decide to install P recovery technology have little possibilities for improving the global environmental impact measured by LCA, since their choice has technical and economic constraints.

This paper aims to provide an industry-oriented methodology able to facilitate knowledge transfer about $\mathrm{P}$ management from the scientific community to the industrial sector, exploiting tools able to deliver quantitative information and enabling each single company to explore its potential pathway to $\mathrm{P}$ recovery and to define a suitable business plan. Consequently, application of the proposed methodology, based on both innovative and consolidated tools, will provide companies the possibility to construct an integrated overview of all the aspects necessary to make the decision to install a full-scale plant for P recovery.

\section{Materials and Methods}

A systematic industry-based methodology to make the full-scale implementation of P recovery technology mainstream was developed using both innovative and consolidate tools to provide complete and quantitative information to support the decision-making process of companies that want to explore P recovery from their wastewater. In particular, the steps of the proposed methodology are described in the following paragraphs and their relation is shown in Figure 1. The main novelty of the proposed methodology is the integration of all the topics necessary for the companies to approach installation of P recovery technology, facilitating knowledge transfer developed in previous researches and reducing the gap between the theoretical framework and practical implementation of $\mathrm{P}$ recovery at the industrial level. The methodology guides companies to collect data and to elaborate on information specific for their situation, helping them construct a quantitative and tailored evaluation of potential scenarios. 


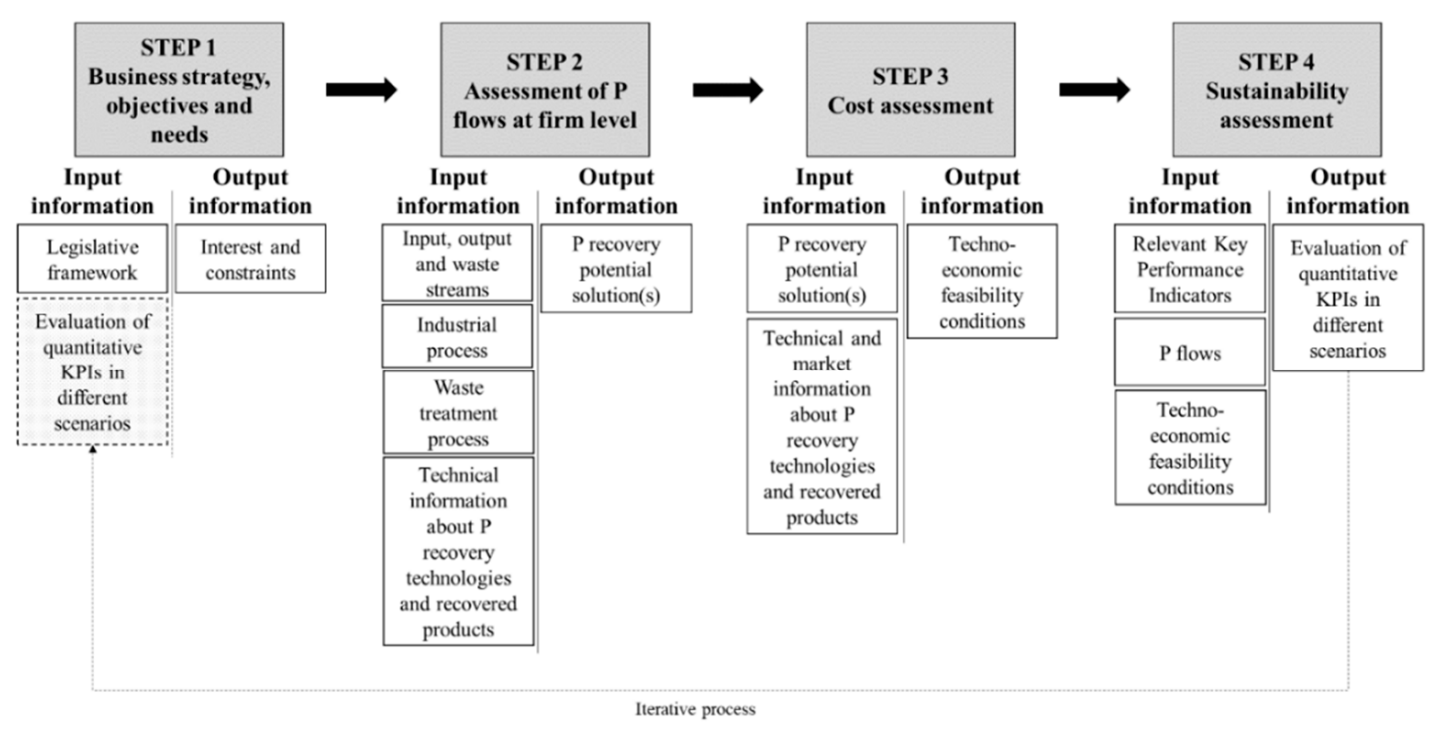

Figure 1. Proposed integrated industry-based methodology to unlock full-scale implementation of $P$ recovery technologies.

\subsection{Step 1-Business Strategy, Objectives and Needs}

According to References [12,14], P recycling could possibly not be the main goal for companies that manage P-rich flows. However, the implementation of P recovery-or rather removal—technology could generate benefits related to the reduction of operational and maintenance issues due to uncontrolled struvite crystallization and/or due to the necessity to not exceed legislative limits about $P$ emissions. Consequently, the focus of the first step of the proposed methodology is on determination of the company interests and needs. Determining if a company is interested only in P removal or also in P recycling is important since it influences the following steps of the method, particularly selection of the suitable P recovery technology. In this stage, opportunities and constraints must be evaluated; consequently, a deep analysis of the legislative framework is necessary to identify specific aspects, such as $\mathrm{P}$ emission limits, end-of-waste criteria and restrictions in the reuse of recovered products. In fact, the complex regulatory framework, characterized by interrelated and overlapping regulations on the regional, national and EU levels, could prevent some business strategies on $\mathrm{P}$ recycling [11], determining for example trade barriers between countries and the need for long and difficult procedures for the approval of waste/secondary raw material transport and reception [12]. The interest in $P$ recovery and the potential sale of recovered by-products influences the choice of the most suitable technology above all from a technical point of view: typology and quality of recovered $P$ become relevant aspects to consider.

\subsection{Step 2-Assessment of P Flows at the Firm Level}

An innovative tool developed by the authors of this paper to provide a quantitative visualization of circular business models and to identify unexplored sustainable solutions is proposed in Reference [45]. The potential of application of the visualisation tool in quantifying circular initiatives, supported by the implementation of digital technologies, has been demonstrated in Reference [46], and it has been integrally applied for the first time to an initiative based on a more sustainable management of plastic waste at a sport event [47]. Due to its flexibility and versatility, this tool is proposed also to describe $P$ recovery, with the aim to measure and visualize $P$-containing flows in the processes of businesses interested in implementing P recovery/removal technology. Each relevant part of the considered industrial process and of the respective waste treatment processes (e.g., wastewater treatment plant) is represented by a stage, as defined in Reference [45]. The tool is based on Material Flow Analysis (MFA). To support the decision-making process of companies, data are considered on an annual basis. Consequently, according to this tool, primary/secondary raw materials (input) and final products 
(output), waste at different steps of their treatment until their discharge/disposal externally, must be known to the company and measured mainly in terms of annual quantity and P concentration [48]. This information feeds the proposed quantitative tool, allowing for immediate visualization of the points in the process where the mass of $\mathrm{P}$ is used or lost, where it must be removed according to legislation and where $P$ could be recovered. Consequently, starting from the interests and the constrains determined in the previous step, integration of this quantitative information with technical features of technologies for P recovery (evaluated with technology providers) allows for the selection of the most suitable options from a technical point of view.

\subsection{Step 3-Cost Assessment of the Suitable Options}

A technically feasible option for P recovery cannot be considered completely suitable if economic feasibility is not also demonstrated [48]. The Net Present Value (NPV) is a consolidated tool used in industries to evaluate and compare investments and their economic return. According to Reference [38], in the $\mathrm{P}$ recovery field, the revenue/cost items to be considered on an annual basis are (i) the revenues derived from the sale of recovered P products; (ii) the ceasing costs related to reduction of sludge quantity recovered as by-products; (iii) the ceasing costs related to reduction of chemical reagents used for $\mathrm{P}$ removal to not exceed legislative limits; (iv) the ceasing costs related to avoided maintenance in removing uncontrolled crystallization of $\mathrm{P}$ at different parts of the plant; (v) the investment cost that includes the equipment, instrumentation, control and safety systems, and building necessary to the "selected" P recovery technologies and the costs for engineering; (vi) the operational and maintenance (O\&M) costs that include energy consumption, chemical reagents necessary in P recovery processes, additional staff and maintenance operations; and (vii) the financial costs. The presence and the values of all items or of part of them depend on the business strategy and interests (step 1) and on the technically feasible solutions that have been chosen after the evaluation in step 2.

\subsection{Step 4-Sustainability Assessment}

The assessment of sustainable impacts facilitates the decision-making process, providing indications about the current situation, the potential in improvement and the implications of proposed solutions. The use of relevant Key Performance Indicators (KPIs) allows for monitoring and development of a strategic framework based on sustainability [49]. The selection of suitable and useful KPIs is fundamental and requires systematic analysis [50]. From an environmental point of view, the application of LCA methodology surely provides a complete and transversal overview of the environmental impacts. The indicators derived from this method, such as climate change, eutrophication, ecotoxicity and others, are defined in References [51,52] as compound indicators, that means aggregated information that combines different impacts into a single measure, typically expressed for a single functional unit. Therefore, these indicators could be not very practical and, providing a system figure, tend to mask specific performance parameters and critical aspects. Consequently, in the scope of the proposed industry-oriented methodology, focused on supporting company decision-making process, more useful KPIs could refer to the evaluation of some performances for the analysed solutions. These KPIs must be easy to use for reporting and for the identification of further improvements. Table 1 shows the KPIs considered relevant for assessment and comparison of P recovery solutions. This list, derived from an analysis of the literature, does not aim to be complete, but it proposes methodological approaches with some examples. 
Table 1. Examples of Key Performance Indicators (KPIs) to assess sustainability of different solutions to remove/recycle P from waste streams. Source: [37,51,53].

\begin{tabular}{|c|c|c|c|}
\hline Typology & KPI & Description & Unit \\
\hline \multirow{6}{*}{ Environmental } & $\begin{array}{l}\text { P concentration in the } \\
\text { discharged wastewater }\end{array}$ & $\begin{array}{l}\text { It must be measured with suitable instrumentation } \\
\text { to compare its value with the legislative limits. }\end{array}$ & $\mathrm{mg} / \mathrm{L}$ \\
\hline & $P$ removal efficiency & $\begin{array}{l}\text { It compares the quantity of } P \text { contained in the } \\
\text { discharged wastewater with the quantity of } P \\
\text { contained in the untreated wastewater (output of } \\
\text { the industrial process). It represents the efficiency } \\
\text { of the entire wastewater treatment plant (WWTP). }\end{array}$ & $\%$ \\
\hline & P recovery technology efficiency & $\begin{array}{l}\text { It compares the quantities of } \mathrm{P} \text { contained in the } \\
\text { effluents upstream and downstream of the selected } \\
\text { P recovery technology. It depends on the } \\
\text { technology and the operating parameters. }\end{array}$ & $\%$ \\
\hline & $P$ use efficiency & $\begin{array}{l}\text { It compares the quantity of } \mathrm{P} \text { contained in the final } \\
\text { products with the total quantity of } \mathrm{P} \text { that enters the } \\
\text { industrial process. It represents the part of } \mathrm{P} \text { that } \\
\text { effectively remains in final products. }\end{array}$ & $\%$ \\
\hline & P load coefficient & $\begin{array}{l}\text { It compares the quantity of P contained in the } \\
\text { discharged wastewater with the total quantity of } \\
\text { final products. It represents the "impact" of final } \\
\text { products in terms of final emissions of P } \\
\text { in wastewater. }\end{array}$ & $\mathrm{mg} \mathrm{P} / \mathrm{kg}$ \\
\hline & Unrecovered $\mathrm{P}$ & $\begin{array}{l}\text { It represents the dispersion of } \mathrm{P} \text { along the process } \\
\text { (industrial and WWTP) and consists of the } \\
\text { unrecoverable part of the total quantity of P that } \\
\text { enters the process. }\end{array}$ & $\%$ \\
\hline \multirow{2}{*}{ Economic } & $\begin{array}{l}\text { Specific costs per amount of } \\
\text { recovered } P\end{array}$ & $\begin{array}{l}\text { It represents the costs necessary to remove/recovery } \\
1 \mathrm{~kg} \text { of } \mathrm{P} \text { with a specific technology and plant. }\end{array}$ & $€ /$ kg P \\
\hline & Incidence of $P$ removal cost & $\begin{array}{l}\text { It compares the cost incidence of } P \text { removal }(€ / \mathrm{m} 3 \\
\text { y) on wastewater disposal }(€ / \mathrm{m} 3 \mathrm{y}) \text {. }\end{array}$ & $\%$ \\
\hline \multirow{2}{*}{ Social } & New jobs & $\begin{array}{l}\text { It refers to the number of potential new jobs } \\
\text { created through full-scale implementation of } \mathrm{P} \\
\text { recovery technologies. }\end{array}$ & $\#$ \\
\hline & $\begin{array}{l}\text { Employee training and } \\
\text { program development }\end{array}$ & $\begin{array}{l}\text { It refers to the number/hours of courses dedicated } \\
\text { to employees acquiring new expertise in the P } \\
\text { removal, recovery and reuse context. }\end{array}$ & $\#$ or h \\
\hline
\end{tabular}

\section{Results}

While the integrated industry-based methodology aims to be systematic, the derived results are strictly related to specific applications, depending on the most suitable solution for each single company [13]. Consequently, to verify the proposed methodology, it was applied to a real industrial case study in the Italian food processing sector (vegetable processing). The insights and conclusions that could be drawn by application of the methodology are therefore specific for this case study, but elaboration of the proposed steps and analysis of the main results could be used as guidelines to replicate the methodology in other industrial cases supporting the diffusion of P recovery technologies. Every step described in Section 2 is implemented in the considered case study. To provide a complete case study having actual quantitative information, a company that has already installed a P recovery technology at full scale was considered. It derives that some phases and considerations within the proposed steps had been already conducted before application of this methodology. In particular, the analysed company undertook evaluation of the insertion of a P recovery technology in 2010; hence, definition of the business strategy and the selection, installation and operation of the P recovery technology were already conducted before this analysis. Both the previous choices and additional steps are reported in the following paragraphs to provide a complete evaluation of the case study and to facilitate methodology replication.

\subsection{Application of Step 1-Business Strategy, Objectives and Needs}

As anticipated, in 2010, the analysed company decided to undertake implementation of a plant for the treatment and valorisation of its waste flows (solid waste and wastewater) through the recovery of 
biogas, treated water and compost and through the production of renewable energy. About wastewater treatment, the company had needed to comply with Italian legislation D. Lgs. 152/2006, which imposes a $\mathrm{P}$ concentration limit on wastewater discharged at $10 \mathrm{mg} / \mathrm{L}$ in both surface water and sewers. Since this limit was exceeded in the wastewater derived from industrial processes, the company decided to implement $\mathrm{P}$ removal technology as an alternative to a reduction in the $\mathrm{P}$ concentration through chemical dosage (e.g., ferric chloride), which makes management of the following aerobic treatment more complex (e.g., due to heavy metal formation). Another Italian legislation (D. Lgs. 264/2016), more recent than the year when the company evaluated its wastewater treatment plant (WWTP), considers the waste from vegetable processes (the sector of the analysed company) as by-products and hence reusable for other products. Nevertheless, the company was not interested to $P$ recycling. After these considerations, the company selected an already commercially available technology based on struvite recovery through chemical precipitation, that is currently operating to not exceed $\mathrm{P}$ emissions in discharged wastewater.

\subsection{Application of Step 2-Assessment of P Flows at the Firm Level}

Data about annual flows of raw materials, final products and waste (both solids and wastewater) have been collected in each relevant phase of the industrial process and in the WWTP of the analysed food company. According to the framework described in Reference [45], assessment of P flows in the selected company involved four stages: (i) the industrial process related to food processing, the wastewater treatment plant composed by (ii) the Up-flow Anaerobic Sludge Blanket (UASB) treatment (iii) and the P removal technology, and (iv) the aerobic treatment. For each stage, analysis of the input and output flows was conducted to assess the annual quantity of contained P. Equation (1) is expressed for the generic flow $i$ (simply adapted from Reference [54]):

$$
P_{i}=\dot{Q}_{i} \cdot p_{i} \cdot 10^{-6}
$$

where $P_{i}$ is the annual quantity of $\mathrm{P}$ associated with flow $\mathrm{i}(\mathrm{kg} / \mathrm{year}), \dot{Q}_{i}$ is the annual flow rate of flow $\mathrm{i}$ (kg/year for solid materials; $1 /$ year for liquid streams), and $p_{i}$ is the average $\mathrm{P}$ concentration in flow $\mathrm{i}$ ( $\mathrm{mg} / \mathrm{kg}$ for solid materials; $\mathrm{mg} / \mathrm{L}$ for liquid streams). Table 2 summarizes the considered input and output flows containing $\mathrm{P}$ for each of the four described stages. For the greatest part of the listed flows, it was possible to collect data to calculate Equation (1), particularly annual flow rates and $P$ concentration. For some ingredients, P content was derived from the literature. Flows difficult to be quantified, such as deposits, losses and sludge content, were derived by the mass-balance principle as the difference between known inputs and outputs. Following these steps, an annual quantity of $P$ $\left(\mathrm{kg} /\right.$ year$\left.-P_{i}\right)$ was associated to every $P$ containing flow, and it can be represented in the visualization tool. For confidentiality, data were normalized by dividing all $P$ quantities for the total of $P$ inputs in the industrial stage (that corresponds to the maximum value). Consequently, according to Reference [45], the height of each stage of the process is proportional to the annual quantity of $\mathrm{P}$ that enters it. Figure 2 shows the setting of the visualization tool for the considered stages. Due to normalization, the reference is the food processing stage in which the maximum quantity of $P$ enters from raw materials and other ingredients. The height of the box that represents the food processing stage has the unit value for this application (1.000 or $100 \%)$. The height of other stages is proportional to both the respective total annual quantity of $P$ that enters them and the unit height of the food processing stage. Taking an example, the annual quantity of $P$ that comes out from UASB in wastewater is $44.8 \%$ of the annual quantity of $\mathrm{P}$ that enters the food processing as raw materials. 
Table 2. List of stages and P containing flows in the industrial process and wastewater treatment plant (WWTP) of the assesses food company.

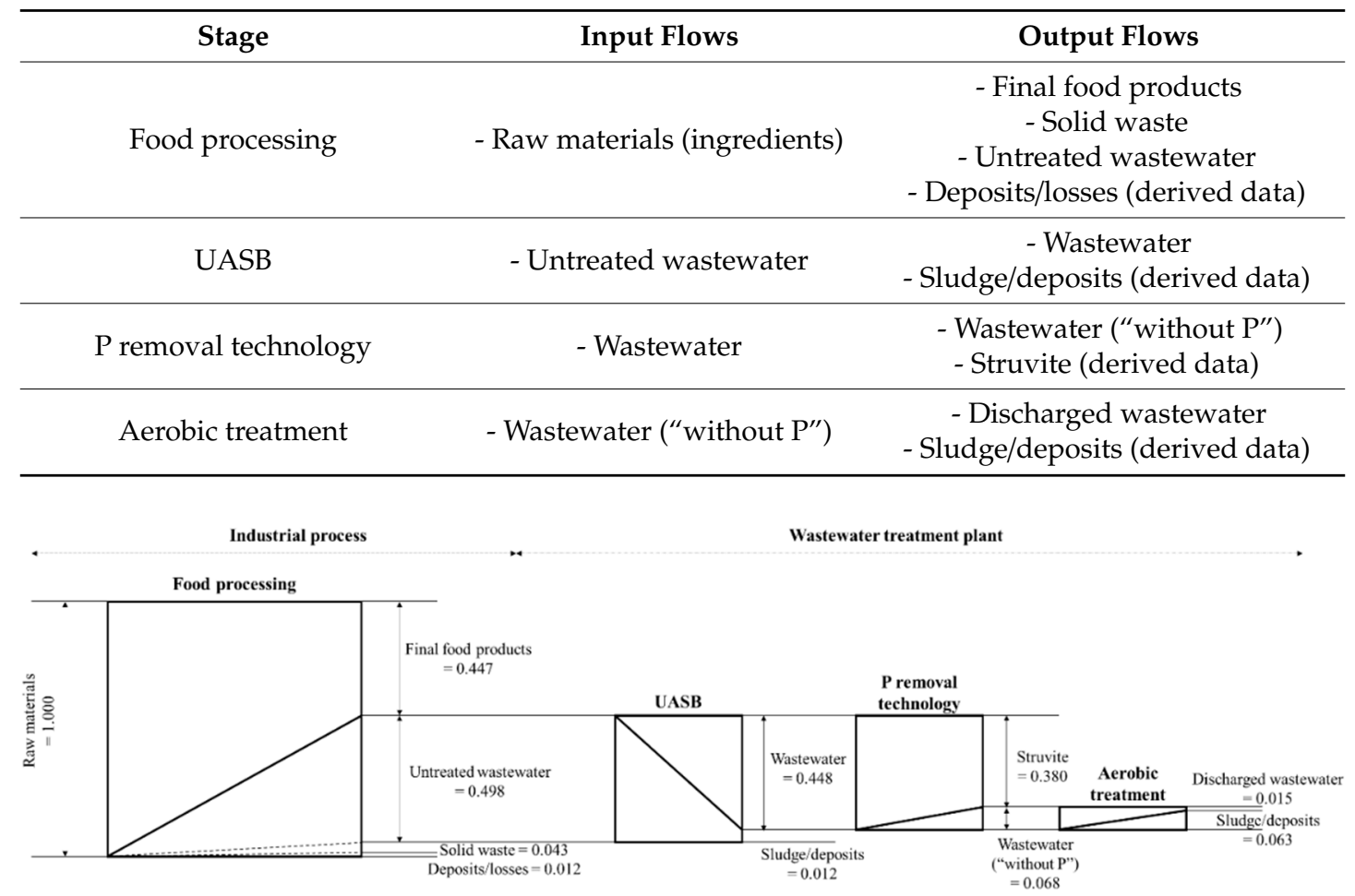

Figure 2. Setting of the visualization tool [45] with quantified P flows for the analysed food company: the numeric values represent the proportion of the annual quantity of $\mathrm{P}$ contained in a specific flow $(\mathrm{kg} \mathrm{P} /$ year) related to the annual quantity of $\mathrm{P}$ that enters food processing $(\mathrm{kg} \mathrm{P} / \mathrm{year})$ at maximum value.

\subsection{Application of Step 3-Cost Assessment of the Suitable Options}

The revenue/cost items described in Section 2.3 have been considered for the selected case study to apply the NPV method. The items related to implementation of the selected P removal technology have been compared to the initial condition, that is, the wastewater treatment without installation of a P recovery technology. The data necessary to calculate the items in Reference [38] were collected, and the annual present value was defined for a 10-year period, considering a suitable discount rate. The total income was derived from the potential sale of the recovered struvite: the maximum recoverable quantity of struvite, evaluated by technology providers for this application, was considered. Another type of income consists of the ceasing cost for reagents (in this case, $\mathrm{FeCl}_{3}$ ), while there are additional costs related to operation and maintenance (O\&M) and, particularly, a relevant item is related to the purchase of the reagents for struvite precipitation (in this case, $\operatorname{Mg}(\mathrm{HO})_{2}$ ), which is supplied directly from the technology provider and must be imported since it is produced in other countries. Table 3 summarizes the main data related to the specific case study used to compare the two scenarios (WWTP without and with P recovery technology) through a differential NPV. In the specific case of the considered company, as affirmed in Section 3.1, the recovered struvite is not sold but managed with sewage sludge and sent to disposal. It means that the revenue item is null. In this configuration, the investment is not economically feasible (the NPV at year 10 was negative). However, the NPV at the end of the analysis period varied in relation to struvite selling price and particularly increased with higher selling prices. Consequently, different scenarios can be evaluated increasing the struvite selling unit price $(€ /$ ton), as shown in Figure 3. 
Table 3. List and values of the main parameters for the Net Present Value (NPV) application.

\begin{tabular}{cc}
\hline Parameter & Value in the Case Study \\
\hline Number of periods & 10 years \\
Discount rate & $6 \%$ \\
Maximum recoverable quantity of struvite (by design) & 170 ton/year \\
Reduction of reagents $\left(\mathrm{FeCl}_{3}\right)$ & $83 \%$ \\
O\&M costs (\% of investment cost) & $5.4 \%$ \\
\hline
\end{tabular}

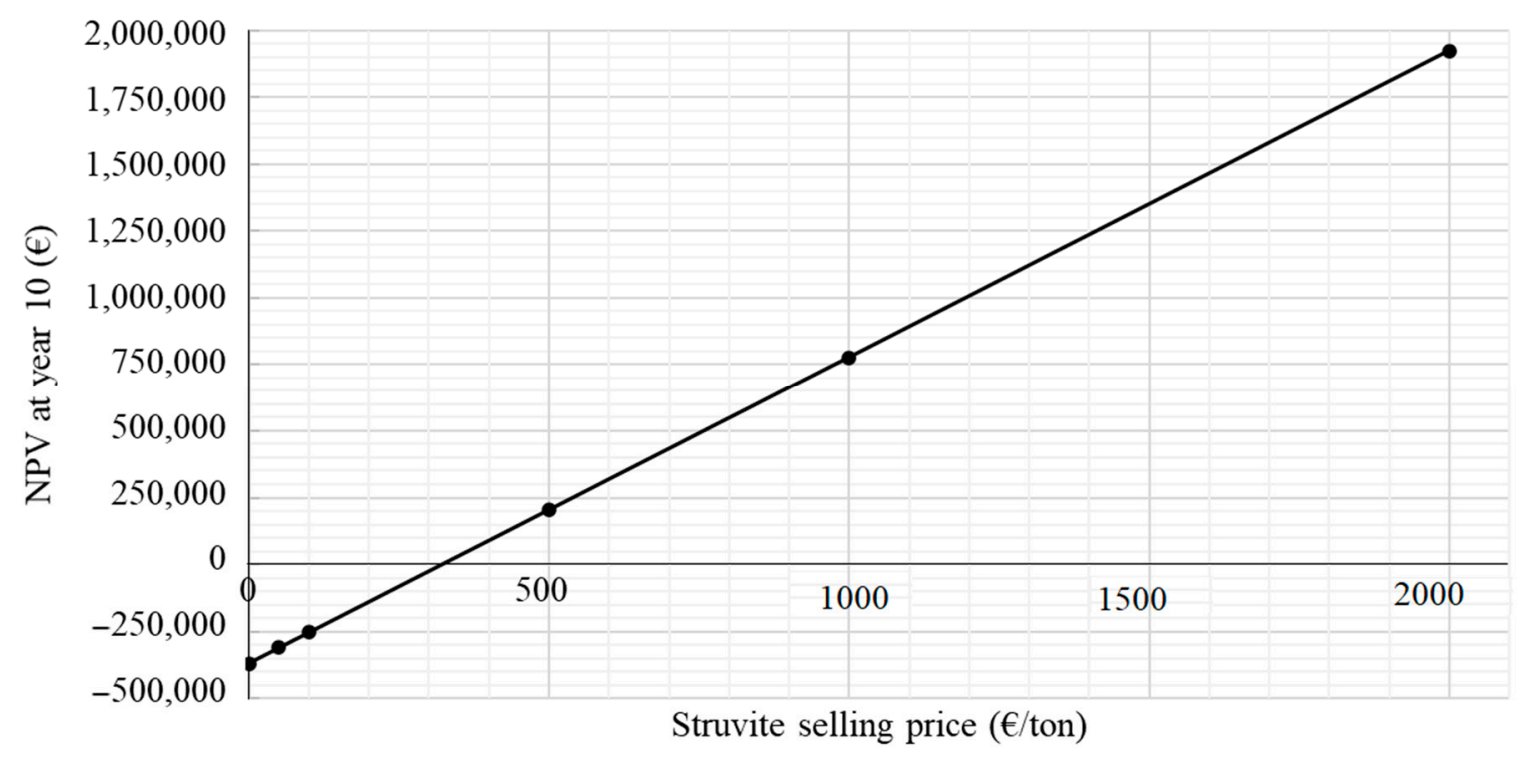

Figure 3. Trend of the NVP of P recovery technology at the end of the period for different values of struvite sale prices.

\subsection{Application of Step 4-Sustainability Assessment}

Implementation of the visualization tool to evaluate P flows and of the NPV method to verify the economic feasibility of the selected case study provide the data necessary to assess the KPIs described in Table 1. In particular, the results of the environmental and economic KPIs are reported in Table 4, while social KPIs are not evaluated. About the environmental assessment, it can be noted that the Italian legislative limitations on P concentration in discharged wastewater is respected; consequently, the main need and objective of the considered company were satisfied with the installation of $P$ removal technology. The P recovery technology efficiency is in line with the performance indicated by the technology provider and with other applications of the same technology. Other KPIs cannot still be compared to other applications, since they are not calculated in other similar studies, so they can be taken as a reference. They represent the quality of processes (P use efficiency, P removal efficiency and unrecovered $\mathrm{P}$ ) and the impact of products (P load coefficient) in the P management sector. From an economic point of view, the incidence of $P$ removal cost in the specific case study is slightly higher than the value cited in Reference [37]. However, also in this case, it can be noted that, even if the economic feasibility of the investment is not demonstrated, the additional costs for $\mathrm{P}$ removal consist of a minor part of wastewater management. Finally, a technological innovation process can reduce the specific costs per amount of recovered $P$ through different effects, such as an increase in recovered struvite with the same costs or a reduction of costs to extract the same quantity of struvite. 
Table 4. Evaluation of the selected KPIs for the analysed food company.

\begin{tabular}{ccc}
\hline Typology & KPI & Value in the Selected Case Study \\
\hline & P concentration in the discharged wastewater (average) & $6.6 \mathrm{mg} / \mathrm{L}$ \\
& P removal efficiency & $96.9 \%$ \\
Environmental & P recovery technology efficiency & $80.1 \%$ \\
& P use efficiency & $44.7 \%$ \\
& P load coefficient & $34.4 \mathrm{mg} \mathrm{P} / \mathrm{kg}$ \\
Economic & Unrecovered P & $13.6 \%$ \\
\hline \multirow{2}{*}{ Specific costs per amount of recovered P } & $0.864 € / \mathrm{kg} \mathrm{P}$ \\
& Incidence of P removal cost & $5.39 \%$ \\
\hline
\end{tabular}

\section{Discussion}

In Reference [55], it is highlighted how, in the general topic of circular economy, single enterprises have a fundamental role in boosting and practically activating circular economy and, hence, a closed $\mathrm{P}$ loop. Due to the complexity and the multidisciplinary approach for a more sustainable P management, different aspects must be considered to guide the companies in the most suitable decision about the recovery of $P$ from their waste streams. Nevertheless, according to Reference [22], an integrated and effective approach to manage $\mathrm{P}$, derived from previous studies, is still not available. The proposed methodology aims to cover this lacking point, exploiting knowledge and tools developed in the scientific literature and adapting them to business needs during the decision-making process. Surely, for evaluation of the impact of current $P$ management and the comparison to alternative scenarios that exploit $\mathrm{P}$ recovery and reuse, a first necessary step is analysing and quantifying the relevant flows and stocks of $\mathrm{P}$ in the anthropogenic cycle to identify the most suitable solutions to exploit the maximum potential. According to Reference [23], in comparison with the typical approach in literature that assesses $\mathrm{P}$ flows on the meso and macro scales, a high-resolution analysis of $\mathrm{P}$ flows is a key aspect to have a clear consideration of the consequential environmental impacts. Due to the differences in products and processes in terms of $\mathrm{P}$ flows, a micro-level analysis, where the system boundaries match the company boundaries, could be more effective in making the implementation of full-scale P recovery technologies mainstream. Application of the visualization tool proposed in Reference [45] allows for mapping P flows at the firm level, not only paying attention at the end of the industrial process, when flows containing $\mathrm{P}$ have already become waste, but also focusing on the efficiency in P use during the process. Application of the visualization tool at the firm level is one of the most innovative features of the proposed methodology, since it makes some covered and unexplored aspects evident. For example, in the considered case study, this approach highlighted that only less than half of the $\mathrm{P}$ contained in the raw materials remains in the final products. Since food processing steps and raw material selection are at the basis of the core business and of the expertise of this company, they should further investigate the possibility to improve this ratio. The visualization tool reveals also a discrepancy between the maximum recoverable quantity of struvite, defined by design, and the quantity of struvite theoretically generated by the P mass quantity extracted by the technology: in particular, considering the chemical composition of the produced struvite, converting the P quantity that comes out from the recovery technology (flow named "struvite" in Figure 2 and corresponding to $38 \%$ of the total $\mathrm{P}$ mass that enters the process), the expected quantity of struvite is greater than the value defined by design (170 ton/year). It means that there is room for improvement in the precipitation phase and its operating conditions.

Technologies based on the recovery of $\mathrm{P}$ from different points at a wastewater treatment plant and different treated effluents have been already developed-some of them already commercially available - and, in the last decade, they gained in popularity thanks to the increased attention of legislation on the $\mathrm{P}$ challenge. Chemical precipitation is the main process to recover $\mathrm{P}$ as struvite, a mineral containing also $\mathrm{N}$, suitable for reuse as a fertilizer [56], as recognized also from the new EU Fertilizer Regulation (2019/1009 [57]). Crystallization of P in the form of struvite is the most applied solutions at full-scale, since it is simple by design and operation and has a good efficiency. 
Theoretical aspects underlying struvite crystallization have been widely analysed in terms of principles of nucleation, crystal growth and the influencing factors, while more recent studies are more focused on the increase in crystallization process efficiency and improvement in struvite quality to facilitate its reuse as a fertilizer [58]. In fact, as highlighted by References [12,35], one of the main barriers in the diffusion of full-scale implementation of $P$ recovery technologies refers to the market side. In fact, although struvite is simple to recover, having few plant complexities and costs compared to technologies based on other principles and having good chemical characteristics to be a secondary raw material, as also recognized by the legislation [57], there are also some limiting technical aspects to address, ensuring a market perspective. Consequently, according to Reference [14], the quality of the derived products, considering also different processes than struvite precipitation, must be considered during strategy definition if the interest of the company is also in recycling P. The precipitation of struvite is a principle on which the technology installed at full scale in the considered case study is also based. Technologies based on forms of P recovered by sewage sludge ashes could be more promising, but they require further research and development to verify the performances obtained at the laband/or pilot-scale and at full-scale plants [27]. Moreover, the recovery of $P$ from ashes requires the mono-incineration of sludge, which, if not already implemented for other objectives, generates high additional costs [37].

It is necessary to highlight that the priority and the interest of some companies could be related to $P$ removal from waste streams and not on P recovery [14]. In the considered company, the installation of $\mathrm{P}$ recovery technology at full scale made it possible to not exceed the legislative limit for $\mathrm{P}$ emissions, which was the main interest, and allowed for some benefits such as a reduction in the complexity of management of the owned WWTP with the use of reagents. Since the main interest of the company was to remove $P$ from its wastewater before its discharge into sewers, the company did not take in consideration the possibility of sale of the recovered form of P; therefore, the quality of derived struvite was not a relevant feature during decision-making process. In the last few years, due to greater attention on the topic, the company started to evaluate the possibility to exploit its "waste" in collaboration with an Italian fertilizer producer. However, the recovered struvite was not directly reusable as fertilizer but required further processing steps involving both the food and the fertilizer producers. In particular, the food processing company must reduce the moisture content of the recovered struvite to ensure its transport while the fertilizer producer must work on the increase in solubility and potassium content for suitable crop yield when used as fertilizer.

From an economic point of view, the results of the assessment in the considered case study confirm previous literature results. As demonstrated, although the cost for P recovery covers a minor part of the wastewater disposal costs, the economic feasibility of a business model based on recovery of $P$ from wastewater and the sale of the recovered product are not ensured when compared to primary $\mathrm{P}$ rocks. The selling price of struvite (or different forms of recovered $\mathrm{P}$ ) is much too high if compared to the price of primary P extracted from mines [32,37,38]. A solution not economically feasible is not implementable for companies unless they are forced by some external reasons, such as legislation. Only associating cost with the external impacts derived from unsustainable P management and from the recovery and reuse of $\mathrm{P}$ becomes economically feasible [38]. If avoided, negative externalities, such as eutrophication, can be inserted in the NVP and business plan as ceasing costs, as proposed in Reference [38], or if even lower quantity and quality of $P$ rocks are considered as suggested in Ref. [13], the feasibility of P recycling cannot be neglected. However, to recognize this value, a strong political intervention is fundamental to further boost $\mathrm{P}$ recovery and reuse [37]. In limiting P recycling in terms of economic aspects, there are also issues related to the market. The fertilizer market is typically traditional, conservative and difficult to change. Consequently, since P rocks are cheaper than the recovered $\mathrm{P}$ products and the latter requires reprocessing before sale as fertilizer, fertilizer producers will remain sceptical towards introducing other forms of $P$ for fertilizer manufacturing [12]. Nevertheless, the increasing demand for fertilizers and the low quality of P rocks surely can contribute to supporting the transition to P recycling [13]. 
To complete this overview on P recovery and hence to provide a comprehensive framework for researchers, technology providers, companies and utilities, and legislators, how much a specific full-scale installation impacts the environment is another fundament requirement to be evaluated [59]. The LCA tool is surely useful to evaluate if the reduction of an environmental issue, such as mineral $\mathrm{P}$ extraction and/or eutrophication, involves its replacement with another issue, such as increased energy and chemical consumption for P recovery. In particular, LCA results can support the comparison of technologies and processes and the identification of improvement solutions, helping legislators in decision-making processes about future actions and strategies [41,59]. However, according to Reference [60] as well as the LCA results, the benefit itself to recover P from waste streams and to reuse it for valuable products cannot be neglected due to the current environmental and socioeconomic critical context and the relevance of P management. To consider this benefit, some KPIs have been selected and evaluated for the case study. This step of the proposed methodology is another innovative aspect. The quantification of KPIs, simple to understand and specifically related to a single or more operation(s), supports the company in the decision on what investment to conduct in the P recovery field, providing the tools to compare different alternatives. Moreover, the KPIs can be upgraded in relation to implemented improvements and technological innovations to monitor the sustainability of the company about $\mathrm{P}$ management over time in relation to thresholds and targets, fixed both internally and externally (e.g., by legislation). The quantitative application of these KPIs, selected as relevant but without ambition to cover the entire topic, can provide useful information for further researches to have an integrated framework of the implications of full-scale implementation of $P$ recovery technology, according to the approach proposed in Reference [22]. From an environmental point of view, application of the LCA method surely completes the analysis with a wider and complete approach that considers also a global impact about $\mathrm{P}$ management, providing useful information for researches, technology providers and policy makers. The determination of social impacts still requires further analysis, not only in the $\mathrm{P}$ field but in general when the focus is sustainability. Due to its importance, social sustainability measurement is increasingly applied to innovation deployment; however, it is still in its infancy [46]. Social impacts of a more sustainable management of $\mathrm{P}$ can be defined on two levels [61]. The first is at the firm level, as described in this paper, that assesses how company activities directly have an effect on local society in the short term. The second is on a national level; P recovery ensures medium- and long-term benefits for the community, such as national resilience and just access to food.

The main implications of this paper are four-fold. (i) Firstly, there is a business implication. The proposed methodology can be used directly by companies interested in evaluating their potential in P recovery from their waste and in investigating recovered $P$ reuse in other sectors, activating also new circular business models. To further facilitate knowledge transfer, to make it mainstream and to reduce the theory-practice gaps, the methodology can be disseminated among practitioners, such as consultancy professionals, to support companies in this evaluation. (ii) The identification of potential in P recovery and reuse at the firm level facilitates also the definition of suitable and tailored policies and financial tools to respond to needs and specialization of companies in a specific geographical area $[62,63]$. (iii) The third implication refers to the scientific community. The methodology can be used by researchers to assess the potential of developments in this field and to facilitate comparison of the obtained results to other studies, for example, when new technologies to recover $P$ with higher efficiency are proposed and analysed and/or a higher quality of recovered $\mathrm{P}$ is achieved, activating improved reuse pathways. The complete and quantitative overview provided by this methodology could support a more rapid diffusion of the proposed solutions, accelerating the shift from lab-/pilot-scale to the full-scale implementation. (iv) Finally, from an academic point of view, the proposed methodology can be used as a kind of exercise for students in training programs about a more sustainable P management with the aim to prepare professionals, enabling a further diffusion of solutions to recover and reuse $\mathrm{P}$. 


\section{Conclusions}

An industry-based methodology to boost full-scale implementation of P recovery technologies was developed and applied to a real case study. The considered company had already installed a P removal technology since it needed to not exceed legislative limits. Further application of the methodology will involve a company that will evaluate the opportunity and the potential of P recovery for the first time. In particular, due to its impact on P management, the dairy sector will be considered. The novelty of this methodology is its integrated approach that involves technological, economic, environmental and social aspects of business innovation in P management. It is necessary to highlight that the quantitative results are strictly related to the specific case study considered in the paper. However, companies interested in evaluating the opportunities to exploit nutrients in their waste can easily replicate the proposed method and find the most suitable solution for their conditions. The most novel feature of this methodology is provided by the application of the innovative visualization tool developed by the University of Bologna. The tool allows for the identification of $\mathrm{P}$ flows at the firm level, highlighting the most critical points in $\mathrm{P}$ management to improve and potentially exploit these streams. The information collected with this tool can be used to determine environmental, economic and social impacts through the evaluation of relevant KPIs. Quantitative information provides evidence to companies about effective benefits and risks, which must be well recognized and known to make an investment. Since the methodology is based on company needs, it could be effectively useful to make $P$ recovery technologies mainstream. In fact, overcoming the lack of awareness about the potential and the value of waste and about the contribution that they could provide for more sustainable $P$ management remains a priority. This set of information is fundamental also for policy makers and financial bodies, which can evaluate both the positive and negative implications of specific solutions, supporting this transition with suitable policies, economic and financial tools for companies.

Author Contributions: A.B. supervised the study and wrote the original draft. J.R. conducted a formal analysis of the results and wrote the original draft. All authors have read and agreed to the published version of the manuscript.

Funding: This research was funded by Prosumer-Techno-economic and environmental feasibility study of Phosphorus recovery and reuse in fertilizers applied to Italian Prosumers (producers and consumers of P) (project n. 200103, 2020), which is financed by EIT Climate KIC—a body of the European Union.

Acknowledgments: The authors acknowledge EIT RawMaterials-A body of the European Union, which funded the project InPhos (No. 17022-2018-2020). In the project, the authors developed knowledge and expertise about P management, useful for elaborating the proposed methodology described in this paper.

Conflicts of Interest: The authors declare no conflict of interest.

\section{References}

1. Baranzelli, C.; Blagoeva, D.; Blengini, G.A.; Ciupagea, C.; Dewulf, J.; Dias, P.; Kayam, Y.; Latunussa, C.E.L.; Mancini, L.; Manfredi, S.; et al. Methodology for Establishing the EU List of Critical Raw Materials: Guidelines; European Commission, Join Research Centre: Brussels, Belgium, 2017; ISBN 978-92-79-68051-9.

2. Li, B.; Dong, S.L.; Huang, Y.F.; Li, P.; Yu, W.; Wang, G.Q.; Young, B. Toward a decision support framework for sustainable phosphorus management: A case study of China. J. Clean. Prod. 2021, 279, 123441. [CrossRef]

3. Günther, S.; Grunert, M.; Müller, S. Overview of recent advances in phosphorus recovery for fertilizer production. Eng. Life Sci. 2018, 18, 434-439. [CrossRef] [PubMed]

4. Mew, M.; Steiner, G.; Geissler, B. Phosphorus Supply Chain-Scientific, Technical, and Economic Foundations: A Transdisciplinary Orientation. Sustainability 2018, 10, 1087. [CrossRef]

5. Rahimpour Golroudbary, S.; El Wali, M.; Kraslawski, A. Rationality of using phosphorus primary and secondary sources in circular economy: Game-theory-based analysis. Environ. Sci. Policy 2020, 106, 166-176. [CrossRef]

6. Robles, Á.; Aguado, D.; Barat, R.; Borrás, L.; Bouzas, A.; Giménez, J.B.; Martí, N.; Ribes, J.; Ruano, M.V.; Serralta, J.; et al. New frontiers from removal to recycling of nitrogen and phosphorus from wastewater in the Circular Economy. Bioresour. Technol. 2020, 300, 122673. [CrossRef] [PubMed] 
7. European Commission. The European Green Deal; COM(2019) 640 Final; European Commission: Brussels, Belgium, 2019.

8. European Commission. A New Circular Economy Action Plan; COM(2020) 98 Final; European Commission: Brussels, Belgium, 2019.

9. Tomei, M.C.; Stazi, V.; Daneshgar, S.; Capodaglio, A.G. Holistic Approach to Phosphorus Recovery from Urban Wastewater: Enhanced Biological Removal Combined with Precipitation. Sustainability 2020, 12, 575. [CrossRef]

10. Ryu, H.-D.; Lim, D.Y.; Kim, S.-J.; Baek, U.-I.; Chung, E.G.; Kim, K.; Lee, J.K. Struvite Precipitation for Sustainable Recovery of Nitrogen and Phosphorus from Anaerobic Digestion Effluents of Swine Manure. Sustainability 2020, 12, 8574. [CrossRef]

11. Smol, M.; Preisner, M.; Bianchini, A.; Rossi, J.; Hermann, L.; Schaaf, T.; Kruopienè, J.; Pamakštys, K.; Klavins, M.; Ozola-Davidane, R.; et al. Strategies for Sustainable and Circular Management of Phosphorus in the Baltic Sea Region: The Holistic Approach of the InPhos Project. Sustainability 2020, 12, 2567. [CrossRef]

12. De Boer, M.A.; Romeo-Hall, A.; Rooimans, T.; Slootweg, J. An Assessment of the Drivers and Barriers for the Deployment of Urban Phosphorus Recovery Technologies: A Case Study of The Netherlands. Sustainability 2018, 10, 1790. [CrossRef]

13. Cieślik, B.; Konieczka, P. A review of phosphorus recovery methods at various steps of wastewater treatment and sewage sludge management. The concept of "no solid waste generation" and analytical methods. J. Clean. Prod. 2017, 142, 1728-1740. [CrossRef]

14. Solon, K.; Volcke, E.I.P.; Spérandio, M.; van Loosdrecht, M.C.M. Resource recovery and wastewater treatment modelling. Environ. Sci. Water Res. Technol. 2019, 5, 631-642. [CrossRef]

15. Paredes, G.; Herrera, R.F. Teaching Multi-Criteria Decision Making Based on Sustainability Factors Applied to Road Projects. Sustainability 2020, 12, 8930. [CrossRef]

16. Van Dijk, K.C.; Lesschen, J.P.; Oenema, O. Phosphorus flows and balances of the European Union Member States. Sci. Total Environ. 2016, 542, 1078-1093. [CrossRef]

17. Wang, Z.; Hartmann, T.E.; Wang, X.; Cui, Z.; Hou, Y.; Meng, F.; Yu, X.; Wu, J.; Zhang, F. Phosphorus flow analysis in the maize based food-feed-energy systems in China. Environ. Res. 2020, 184, 109319. [CrossRef] [PubMed]

18. Cordell, D. The Story of Phosphorus: Missing global governance of a critical resource. In Proceedings of the SENSE Earth Systems Governance, Amsterdam, The Netherlands, 24-31 August 2008; pp. 1-25.

19. Klinglmair, M.; Vadenbo, C.; Astrup, T.F.; Scheutz, C. An MFA-based optimization model for increased resource efficiency: Phosphorus flows in Denmark. Resour. Conserv. Recycl. 2017, 122, 1-10. [CrossRef]

20. Theobald, T.F.H.; Schipper, M.; Kern, J. Phosphorus flows in Berlin-Brandenburg, a regional flow analysis. Resour. Conserv. Recycl. 2016, 112, 1-14. [CrossRef]

21. Huang, C.-L.; Gao, B.; Xu, S.; Huang, Y.; Yan, X.; Cui, S. Changing phosphorus metabolism of a global aquaculture city. J. Clean. Prod. 2019, 225, 1118-1133. [CrossRef]

22. Wu, H.; Zhang, Y.; Yuan, Z.; Gao, L. A review of phosphorus management through the food system: Identifying the roadmap to ecological agriculture. J. Clean. Prod. 2016, 114, 45-54. [CrossRef]

23. Wu, J.; Hartmann, T.E.; Chen, W.-S. Toward sustainable management of phosphorus flows in a changing rural-urban environment: Recent advances, challenges, and opportunities. Curr. Opin. Environ. Sustain. 2019, 40, 81-87. [CrossRef]

24. Bolzonella, D.; Cecchi, F. Treatment of food processing wastewater. In Handbook of Waste Management and Co-Product Recovery in Food Processing; Elsevier: Amsterdam, The Netherlands, 2007; pp. 573-596, ISBN 978-1-84569-025-0.

25. Altech Environmental Consulting Ltd. A Review of Wastewater Management and Best Practices for Dischargers in the Food Processing Sector; Altech Environmental Consulting Ltd.: North York, ON, Canada, 2005.

26. Valta, K.; Kosanovic, T.; Malamis, D.; Moustakas, K.; Loizidou, M. Water consumption and wastewater generation and treatment in the Food and Beverage Industry. Desalin. Water Treat 2013, 53, 12.

27. Carrillo, V.; Fuentes, B.; Gómez, G.; Vidal, G. Characterization and recovery of phosphorus from wastewater by combined technologies. Rev. Environ. Sci. Biotechnol. 2020, 19, 389-418. [CrossRef]

28. Ma, W.; Ma, L.; Li, J.; Wang, F.; Sisák, I.; Zhang, F. Phosphorus flows and use efficiencies in production and consumption of wheat, rice, and maize in China. Chemosphere 2011, 84, 814-821. [CrossRef] [PubMed] 
29. Chowdhury, R.B. A multi-year phosphorus flow analysis of a key agricultural region in Australia to identify options for sustainable management. Agric. Syst. 2018, 161, 42-60. [CrossRef]

30. Jeong, Y.-S.; Matsubae-Yokoyama, K.; Kubo, H.; Pak, J.-J.; Nagasaka, T. Substance flow analysis of phosphorus and manganese correlated with South Korean steel industry. Resour. Conserv. Recycl. 2009, 53, 479-489. [CrossRef]

31. Morse, G.K.; Brett, S.W.; Guy, J.A.; Lester, J.N. Review: Phosphorus removal and recovery technology. Sci. Total Environ. 1998, 212, 69-81.

32. Egle, L.; Rechberger, H.; Krampe, J.; Zessner, M. Phosphorus recovery from municipal wastewater: An integrated comparative technological, environmental and economic assessment of P recovery technologies. Sci. Total Environ. 2016, 571, 522-542. [CrossRef]

33. European Sustainable Phosphorus Platform. DPP-NNP Phosphorus Recovery Technology Catalogue. Available online: https:/phosphorusplatform.eu/images/download/ESPP-NNP-DPP_P-recovery_tech_ catalogue_v_25_2_2020.pdf (accessed on 6 November 2020).

34. Siciliano, A.; Limonti, C.; Curcio, G.M.; Molinari, R. Advances in Struvite Precipitation Technologies for Nutrients Removal and Recovery from Aqueous Waste and Wastewater. Sustainability 2020, 12, 7538. [CrossRef]

35. Ghosh, S.; Lobanov, S.; Lo, V.K. An overview of technologies to recover phosphorus as struvite from wastewater: Advantages and shortcomings. Environ. Sci. Pollut. Res. 2019, 26, 19063-19077. [CrossRef]

36. Chrispim, M.C.; Scholz, M.; Nolasco, M.A. Phosphorus recovery from municipal wastewater treatment: Critical review of challenges and opportunities for developing countries. J. Environ. Manag. 2019, 248, 109268. [CrossRef]

37. Nättorp, A.; Remmen, K.; Remy, C. Cost assessment of different routes for phosphorus recovery from wastewater using data from pilot and production plants. Water Sci. Technol. 2017, 76, 413-424. [CrossRef]

38. Molinos-Senante, M.; Hernandez-Sancho, F.; Sala-Garrido, R.; Garrido-Baserba, M. Economic Feasibility Study for Phosphorus Recovery Processes. Ambio 2011, 40, 408-416. [CrossRef] [PubMed]

39. Shu, L.; Schneider, P.; Jegatheesan, V.; Johnson, J. An economic evaluation of phosphorus recovery as struvite from digester supernatant. Bioresour. Technol. 2006, 97, 2211-2216. [CrossRef] [PubMed]

40. Sena, M.; Hicks, A. Life cycle assessment review of struvite precipitation in wastewater treatment. Resour. Conserv. Recycl. 2018, 139, 194-204. [CrossRef]

41. Lin, Y.; Guo, M.; Shah, N.; Stuckey, D.C. Economic and environmental evaluation of nitrogen removal and recovery methods from wastewater. Bioresour. Technol. 2016, 215, 227-238. [CrossRef]

42. Rashid, S.S.; Liu, Y.-Q.; Zhang, C. Upgrading a large and centralised municipal wastewater treatment plant with sequencing batch reactor technology for integrated nutrient removal and phosphorus recovery: Environmental and economic life cycle performance. Sci. Total Environ. 2020, 749, 141465. [CrossRef]

43. Sørensen, B.L.; Dall, O.L.; Habib, K. Environmental and resource implications of phosphorus recovery from waste activated sludge. Waste Manag. 2015, 45, 391-399. [CrossRef]

44. Pradel, M.; Aissani, L. Environmental impacts of phosphorus recovery from a "product" Life Cycle Assessment perspective: Allocating burdens of wastewater treatment in the production of sludge-based phosphate fertilizers. Sci. Total Environ. 2019, 656, 55-69. [CrossRef]

45. Bianchini, A.; Rossi, J.; Pellegrini, M. Overcoming the Main Barriers of Circular Economy Implementation through a New Visualization Tool for Circular Business Models. Sustainability 2019, 11, 6614. [CrossRef]

46. Rossi, J.; Bianchini, A.; Guarnieri, P. Circular Economy Model Enhanced by Intelligent Assets from Industry 4.0: The Proposition of an Innovative Tool to Analyze Case Studies. Sustainability 2020, 12, 7147. [CrossRef]

47. Bianchini, A.; Rossi, J. Design, implementation and assessment of a more sustainable model to manage plastic waste in sport events. J. Clean. Prod. 2021, 281, 125345.

48. Li, B.; Udugama, I.A.; Mansouri, S.S.; Yu, W.; Baroutian, S.; Gernaey, K.V.; Young, B.R. An exploration of barriers for commercializing phosphorus recovery technologies. J. Clean. Prod. 2019, 229, 1342-1354. [CrossRef]

49. Stanchev, P.; Vasilaki, V.; Egas, D.; Colon, J.; Ponsá, S.; Katsou, E. Multilevel environmental assessment of the anaerobic treatment of dairy processing effluents in the context of circular economy. J. Clean. Prod. 2020, 261, 121139. [CrossRef]

50. Janjua, S.Y.; Sarker, P.K.; Biswas, W.K. Development of triple bottom line indicators for life cycle sustainability assessment of residential bulidings. J. Environ. Manag. 2020, 264, 110476. [CrossRef] [PubMed] 
51. Waste and Resources Action Programme (WRAP). Recyclability Efficiency Metric; Waste and Resources Action Programme (WRAP): Banbury, UK, 2008.

52. Feiz, R.; Johansson, M.; Lindkvist, E.; Moestedt, J.; Paledal, S.N.; Svensson, N. Key performance indicators for biogas production-Methodological insights on the life-cycle analysis of biogas production from source-separated food waste. Energy 2020, 200, 117462. [CrossRef]

53. Guarnieri, P.; Pagani, R.N.; Santos, R.R.; Campos, E.A.R.; Paula, I.C.; Cerqueira-Streit, J.A. A survey of indicators to measure the social dimension of Triple Bottom Line. In Proceedings of the International Conference of Resources Sustainability_ICRS 2020, Dublin, Ireland, 30 June-2 July 2020.

54. Brunner, P.H.; Rechberger, H. Practical Handbook of Material Flow Analysis; Advanced Methods in Resource and Waste Management; CRC/Lewis: Boca Raton, FL, USA, 2004; ISBN 978-1-56670-604-9.

55. Liang, W.; Zhao, G.; Hong, C. Performance assessment of circular economy for phosphorus chemical firms based on VIKOR-QUALIFLEX method. J. Clean. Prod. 2018, 196, 1365-1378. [CrossRef]

56. Zin, M.M.T. Struvite production from food processing wastewater and incinerated sewage sludge ash as an alternative $\mathrm{N}$ and P source: Optimization of multiple resources recovery by response surface methodology. Process Saf. Environ. Prot. 2019, 126, 242-249.

57. Regulation (EU) 2019/of the European Parliament and of the Council of 5 June 2019 Laying down Rules on the Making Available on the Market of EU Fertilising Products and Amending Regulations (EC) No 1069/2009 and (EC) No 1107/2009 and Repealing Regulation (EC) No 2003/2003; Official Journal of the European Union: Brussels, Belgium, 2019.

58. Peng, L.; Dai, H.; Wu, Y.; Peng, Y.; Lu, X. A comprehensive review of phosphorus recovery from wastewater by crystallization processes. Chemosphere 2018, 197, 768-781. [CrossRef]

59. Amann, A.; Zoboli, O.; Krampe, J.; Rechberger, H.; Zessner, M.; Egle, L. Environmental impacts of phosphorus recovery from municipal wastewater. Resour. Conserv. Recycl. 2018, 130, 127-139. [CrossRef]

60. Sena, M.; Seib, M.; Noguera, D.R.; Hicks, A. Environmental impacts of phosphorus recovery through struvite precipitation in wastewater treatment. J. Clean. Prod. 2021, 280, 124222. [CrossRef]

61. Kolotzek, C.; Helbig, C.; Thorenz, A.; Reller, A.; Tuma, A. A company-oriented model for the assessment of raw material supply risks, environmental impact and social implications. J. Clean. Prod. 2018, 176, 566-580. [CrossRef]

62. Fan, Y.; Ni, Z.; Wang, S.; Zhang, J.; Wu, S. Whole process phosphorus management strategy construction with phosphorus load characteristics, driver and efficiency from the material flow perspective. J. Clean. Prod. 2021, 279, 122896. [CrossRef]

63. Boh, M.Y.; Clark, O.G. Nitrogen and phosphorus flows in Ontario's food systems. Resour. Conserv. Recycl. 2020, 154, 104639. [CrossRef]

Publisher's Note: MDPI stays neutral with regard to jurisdictional claims in published maps and institutional affiliations.

(C) 2020 by the authors. Licensee MDPI, Basel, Switzerland. This article is an open access article distributed under the terms and conditions of the Creative Commons Attribution (CC BY) license (http://creativecommons.org/licenses/by/4.0/). 